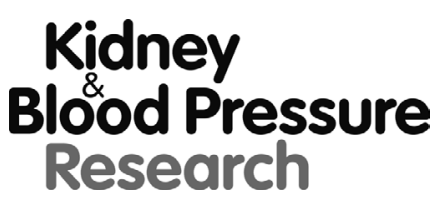

Kidney Blood Press Res 2018;43:594-605

DOI: $10.1159 / 000488965$

Published onlIne: 17 April, 2018

Accepted: 5 April, 2018

This article is licensed under the Creative Commons Attribution-NonCommercial-NoDerivatives 4.0 International License (CC BY-NC-ND) (http//www.kargercom/Services/OpenAccessLicense). Usage and distribution for commercial purposes as well as any distribution of modified material requires written permission.

\title{
Paritaprevir/Ritonavir/Ombitasvir Plus Dasabuvir Regimen in the Treatment of Genotype 1 Chronic Hepatitis C Infection in Patients with Severe Renal Impairment and End-Stage Renal Disease: a Real-Life Cohort
}

\author{
Jan Sperla Miluse Kreidlovab ${ }^{\mathrm{b}} \quad$ Dusan Merta $^{\mathrm{c}} \quad$ Klara Chmelova $^{\mathrm{a}}$ \\ Renata Senkerikova ${ }^{a}$ Sona Frankova ${ }^{a}$ \\ aDepartment of Hepatogastroenterology, Institute for Clinical and Experimental Medicine, Prague, \\ bInstitute of Medical Biochemistry and Laboratory Medicine, Charles University and General University \\ Hospital in Prague, 'Department of Anesthesiology, Resuscitation and Intensive Care, Institute for \\ Clinical and Experimental Medicine, Prague, Czech Republic
}

\section{Key Words}

Ombitasvir • Paritaprevir • Dasabuvir $・$ Hepatitis $C \cdot$ Genotype $1 \cdot$ Haemodialysis

\begin{abstract}
Background/Aims: Chronic hepatitis C (HCV) virus infection reactivates under immunosuppressive drugs and therefore has a negative impact on long-term survival of kidney transplant recipients. Treatment-induced clearance of hepatitis $\mathrm{C}$ virus (HCV) in kidney transplant candidates prevents virus reactivation after transplantation. Paritaprevir/Ritonavir/ Ombitasvir with Dasabuvir (PrOD) represents a highly effective treatment regimen for HCV genotype 1 (GT1), also suitable for patients with end-stage renal disease (ESRD). Serious drugdrug interactions may represent a limiting factor of this regimen. The aim of this retrospective study was to evaluate safety, efficacy and drug-drug interactions management associated with PrOD treatment in the Czech real-world cohort. Methods: Emphasizing concomitant medication adjustment, we described the treatment course with PrOD regimen in 23 patients (4 with CKD4 and 19 on maintenance haemodialysis) infected with HCV GT1 (21 GT1b, 2 GT1a), 18 males and 5 females with an average age of 53.7 years. Six patients had compensated liver cirrhosis and 3 of them were liver transplant recipients. Results: All 23 patients completed the 12-week treatment and achieved sustained virological response 12 weeks after the
\end{abstract}




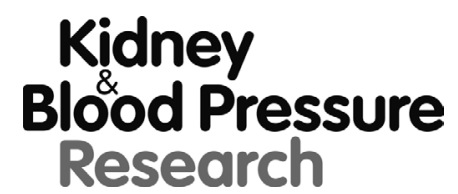

\begin{tabular}{l|l}
\hline Kidney Blood Press Res 2018;43:594-605 \\
\hline \begin{tabular}{l|l} 
DOI: 10.1159/000488965 & (c) 2018 The Author(s). Published by S. Karger AG, Basel \\
Published onlıne: 17 April, 2018 & ww.karger.com/kbr
\end{tabular} \\
\hline
\end{tabular}

Sperl et al.: Anti-HCV Therapy in Haemodialysed Patients

treatment (SVR12 rate 100\%). None of the patients presented with a significant decrease in haemoglobin level, white blood cell and platelet count during the treatment period. The most frequent adverse events were nausea, hypotension, diarrhoea, and hyperkalemia. Four patients presented with a serious adverse event unrelated to the antiviral drugs (salmonellosis, non-functional kidney graft rejection, early gastric cancer, renal cyst infection, initiation of haemodialysis). Concomitant medication had to be modified with the treatment initiation in 10 out of 23 (43.5\%) patients (calcium channel blockers, ACE inhibitors, statins, diuretics, tacrolimus); four patients required further adjustment of antihypertensive drugs or tacrolimus dosage on-treatment. Conclusion: PrOD regimen demonstrated an excellent efficacy and good tolerability. Both prospective adjustment of concomitant medication and further ontreatment adjustment allowed for a safe treatment course.

(C) 2018 The Author(s)

Published by S. Karger AG, Basel

\section{Introduction}

Long-term observational studies confirmed worse survival of HCV-infected kidney transplant recipients in comparison with those without HCV infection [1-2]. Successful HCV treatment in the kidney transplant candidates, the majority of them being on maintenance haemodialysis, is the best way to prevent HCV reactivation after kidney transplantation. Unfortunately, only a small proportion of HCV infected patients underwent antiviral treatment in the era of interferon-based regimens owing to the low efficacy and poor tolerability of the treatment [3-4]. Development of direct-acting antivirals (DAA) has represented major progress in the treatment of chronic hepatitis $\mathrm{C}$ (HCV) infection over the last five years. DAA-based regimens showed an excellent efficacy and tolerability also in specific group of patients who could not be treated with an interferon-based regimen in the past. An accurate selection of the DAA-based regimen, with respect to the HCV genotype, patient's comorbidities and concomitant medication, seems to be crucial for successful treatment [5]. Paritaprevir/Ritonavir/Ombitasvir (Viekirax ${ }^{\mathrm{TM}}$, Abbvie Ltd., Maidenhead, Great Britain) with Dasabuvir (Exviera' ${ }^{\mathrm{TM}}$, Abbvie Ltd., Maidenhead, Great Britain) is a triple DAAs combination (PrOD) approved in 2015 for the treatment of chronic HCV infection. PrOD regimen consists of a NS3/4A serine protease inhibitor boosted by Ritonavir, an NS5A protein inhibitor, and an NS5B non-nucleoside polymerase inhibitor. The PrOD combination, with or without Ribavirin (RBV), showed high antiviral efficacy in patients infected with HCV genotype 1, including those with liver cirrhosis, HIV coinfection, and liver transplant [6-10]. The favourable efficacy profile of PrOD is pronounced especially in patients infected with HCV subtype $1 \mathrm{~b}$, who achieved sustained virological response (SVR) in $100 \%$ without RBV addition even if they had liver cirrhosis [11]. The presence of basal resistant substitutions in the virus genome has no significant influence on the antiviral efficacy of the PrOD regimen [12]. Hepatic metabolism plays a crucial role in the elimination of PrOD; therefore, no dose adjustment is required in patients with severe renal impairment. The high antiviral efficacy and favourable safety profile of PrOD was also demonstrated in patients with severe renal impairment as well as in patients on maintenance haemodialysis infected with HCV genotype 1 (95\% SVR rate) in a prospective registration trial [13]. Recently published real-world cohort studies showed similar data on PrOD efficacy, safety, and tolerability in haemodialysed patients [14-17]. A substantial number of drug-drug interactions represents the only limitation of PrOD regimen [18]. The hepatic metabolism of PrOD causes changes in liver enzyme activities and, therefore, modifies the elimination of other drugs.

Paritaprevir and Ritonavir are mostly metabolized through the CYP3A system. The primary role of Ritonavir in the fixed-dose combination is CYP3A system inhibition so that Paritaprevir exposition is decreased and its once-daily administration is allowed. Paritaprevir is a substrate and inhibitor of organic anion transporting polypeptide (OATP) 1B1/B3, P-glycoprotein (P-gp), and breast cancer resistance protein (BCRP). Ritonavir also inhibits P-gp and BCRP. Dasabuvir is mostly metabolized by CYP2C8 and partially by CYP3A4 and is 


\section{Kidney \\ Blood Pressure Research}

Sperl et al.: Anti-HCV Therapy in Haemodialysed Patients

also a P-gp and BCRP inhibitor. Ombitasvir undergoes amide hydrolysis followed by oxidative metabolism. PrOD should not be administered concomitantly with strong CYP3A4 inducers or strong CYP2C8 inhibitors. PrOD has a drug-drug interaction with some antihypertensive drugs, antiarrhythmics, antiepileptics, statins, and immunosuppressants [19, 20].

Patients with severe renal impairment and haemodialysed patients represent a special groups of HCV patients with a high risk of drug-drug interactions. In general, these patients are of older age with frequent comorbidities and abundant concomitant medication [21,22]. We evaluated the safety and efficacy of PrOD regimen in a group of 23 patients, including 4 patients with severe renal impairment and 19 patients on maintenance haemodialysis, all infected with HCV genotype 1. We describe in detail the drug-drug interactions management, which was the crucial point in the PrOD treatment in this group of patients.

\section{Materials and Methods}

\section{Study design and eligibility of patients}

We retrospectively evaluated 23 patients with chronic kidney disease (CKD) [23]; 4 of them with severe renal impairment (CKD4) and 19 on maintenance haemodialysis (CKD5). All patients were referred to antiviral treatment as kidney transplant candidates before enlistment for kidney transplantation from July 2015 to August 2016. The cohort consisted of 18 males and 5 females with an average age of 53.7 years (range 22-69). The mean duration of the haemodialysis period was 123 months (range 2-420 months). Eleven patients resumed maintenance haemodialysis after previously having undergone kidney transplant with subsequent graft failure. Six out of 11 patients had non-functional kidney graft in situ. Three out of 23 patients had undergone liver transplantation owing to liver cirrhosis C. All the liver transplant recipients had compensated cirrhosis of the graft, i.e. they had normal synthetic liver graft function at the time of the antiviral treatment. They were all on a tacrolimus-based immunosuppressive therapy. All patients were Caucasian, infected with HCV genotype 1 (20 patients genotype $1 \mathrm{~b}, 2$ patients genotype $1 \mathrm{a}, 1$ patient unspecified). None of the patients had HBV or HIV coinfection. The median reported duration of HCV infection was 23 years (range 1-35), 12 patients contracted HCV infection on haemodialysis, 4 patients reported intravenous drug use in the past, 1 patient had transfusion-borne infection before 1992, and 5 patients

Table 1. Baseline patients'characteristics. HCV, Hepatitis C virus; IQR, Interquartile range; CKD, Chronic kidney disease; GFR, Glomerular Filtration Rate calculated according to Cockcroft-Gault formula

\begin{tabular}{|c|c|}
\hline Variable & \\
\hline Men & $18(78 \%)$ \\
\hline Age, years (mean, range) & $53.7(22-69)$ \\
\hline Time from HCV diagnosis, years (median, range) & $23(1-35)$ \\
\hline Baseline ALT activity, serum, IU/mL (mean, range) & $53(18-180)$ \\
\hline Baseline HCV RNA & 785,500 \\
\hline (IU/mL, median, IQR) & $(71,800-3,065,000)$ \\
\hline \multicolumn{2}{|l|}{ HCV genotype } \\
\hline 1 (subtype not specified) & $1(4.3 \%)$ \\
\hline $1 \mathrm{a}$ & $2(8.7 \%)$ \\
\hline $1 \mathrm{~b}$ & $20(87 \%)$ \\
\hline \multicolumn{2}{|l|}{ Fibrosis stage (Metavir score) } \\
\hline F1 & $8(34.8 \%)$ \\
\hline $\mathrm{F} 2$ & $5(21.7 \%)$ \\
\hline F3 & $2(8.7 \%)$ \\
\hline F4 & $6(26.1 \%)$ \\
\hline Not assessed & $2(8.7 \%)$ \\
\hline \multicolumn{2}{|l|}{ CKD stage } \\
\hline CKD4 & $4(17.4 \%)$ \\
\hline CKD5 (on haemodialysis) & $19(82.6 \%)$ \\
\hline \multicolumn{2}{|l|}{ Baseline GFR in CKD4 patients, $\mathrm{ml} / \mathrm{min}$. (mean, range) } \\
\hline $\begin{array}{l}\text { Erythropoietin or darbepoetin } \\
\text { at baseline }\end{array}$ & $7(30.4 \%)$ \\
\hline $\begin{array}{l}\text { Baseline haemoglobin concentration } \\
\text { (g/L, mean, range) }\end{array}$ & 132 (89-189) \\
\hline Diabetes & $8(34.8 \%)$ \\
\hline Arterial hypertension & $16(69.6 \%)$ \\
\hline Arrhythmia & $2(8.7 \%)$ \\
\hline Dyslipidemia & $3(13.0 \%)$ \\
\hline Previous kidney transplant & $11(47.8 \%)$ \\
\hline Previous liver transplant & $3(13.0 \%)$ \\
\hline \multicolumn{2}{|l|}{ Previous antiviral treatment } \\
\hline Treatment-naïve & $14(60.9 \%)$ \\
\hline Treatment-experienced & $9(39.1 \%)$ \\
\hline \multicolumn{2}{|l|}{ Antiviral treatment } \\
\hline Paritaprevir/Ritonavir/Ombitasvir/Dasabuvir & \\
\hline with Ribavirin & $7(30.4 \%)$ \\
\hline without Ribavirin & $16(69.6 \%)$ \\
\hline
\end{tabular}




\section{Kidney Blood Pressure Research}

had unknown mode of infection. Eleven of the 23 patients had normal baseline ALT activity, among the remaining 12 patients with elevated baseline ALT activity, none exceeded 5 times upper limit of normal ALT value. Median pretreatment HCV RNA level was 785,500 UI/ml (interquartile range 71,800-3,065,000 $\mathrm{IU} / \mathrm{ml}$ ). Nine patients failed previous peginterferon- $\alpha$ and RBV therapy ( 6 nullresponders, 3 relapsers), 14 patients were HCV treatment-naïve. Baseline patients' characteristics including significant comorbidities are summarized in Table 1.

Pretreatment stage of liver fibrosis was assessed in 21 out of 23 patients with shear-wave elastography (Aixplorer ${ }^{\circledast}$, SuperSonic Imagine, Aix-en-Provence, France). Two patients suffered from polycystic liver disease; therefore, it was not possible to perform liver stiffness measurement. Liver fibrosis stage (F1F4) was derived from the liver stiffness values in $\mathrm{kPa}$ obtained by shear-wave elastography based on the table provided by the device manufacturer [24]. Six patients had liver cirrhosis; all six cirrhotic patients were infected with genotype $1 \mathrm{~b}$ and had well compensated liver disease with no signs of proteosynthetic dysfunction (albumin, bilirubin, and prothrombin time values within normal ranges), ascites, or encephalopathy.

All patients were treated with PrOD with or without RBV for 12 weeks. All antivirals were administered in accordance with the European prescribing information $[19,20]$ effective at the time of treatment initiation with the exception of liver transplant recipients who were also treated for 12 weeks instead of 24 weeks. The shortening of treatment period in liver transplant recipients was in accordance with EASL 2015 Guidelines [25] which were effective at the time of treatment initiation. The doses of the administered drugs were as follows: Paritaprevir/Ritonavir/Ombitasvir 150/100/25 mg once a day and Dasabuvir 250 mg twice a day. RBV was administered to two non-cirrhotic patients with genotype 1a and to 5 out of 6 cirrhotic patients infected with genotype $1 \mathrm{~b}$. All the liver transplant recipients were treated with RBV. The dose of RBV was reduced to $200 \mathrm{mg}$ twice a week according to renal function and its tolerability in the previous course of therapy. Sustained virological response (SVR) was assessed as HCV RNA negativity 12 weeks post-treatment.

In all patients, the concomitant medication was checked for potential drug-drug interactions with the effective PrOD Summary of Product Characteristics (SPC). The concomitant medication was classified into three groups: contraindicated administration with PrOD (statins, amiodarone), administration possible with dose adjustment (ACE inhibitors, angiotensin-II receptor inhibitors, calcium channel blockers, diuretics, and tacrolimus), and drugs without anticipated interactions (omeprazole, aspirin, erythropoiesisstimulating agents [ESA]). The initial adjustment of concomitant medication was performed on the day of treatment initiation. Further medication adjustment was done on-treatment according to the physical examination and laboratory parameters. The initial dose of tacrolimus was $0.5 \mathrm{mg}$ weekly and was further adjusted according to tacrolimus blood levels, which were assessed on a weekly basis in the first month and then monthly (or more frequently), if needed.

\section{Laboratory assessment}

HCV RNA was assessed by the Roche COBAS ${ }^{\circledR}$ AmpliPrep/COBAS $®$ TaqMan ${ }^{\circledR}$ HCV Quantitative Test v2.0 (Roche Molecular Systems Inc., Branchburg, NJ, USA) at baseline, at weeks 4, 8, and 12 of therapy and 12 weeks after the end of therapy. HCV genotype was assessed before treatment initiation using the SIEMENS Versant ${ }^{\circ}$ HCV Genotype 2.0 Assay (LiPA) (Siemens Healthcare Diagnostics Inc., Tarrytown, NY, USA).

\section{Safety evaluation}

All patients were regularly monitored for treatment efficacy and side effects at baseline, treatment weeks 4, 8, and 12 and 12 weeks after the end of therapy. Apart from query on medical history, side effects, and safety and efficacy of laboratory analyses, each visit consisted of overview of concomitant medication. This included a check of the monthly records provided by the haemodialysis units containing complete concomitant medication overview and the course of haemodialysis therapy. The patients underwent physical examination at each visit including body weight and blood pressure measurement. Laboratory 


\section{Kidney Blood Pressure Research}

assessment at each visit included among others blood count, prothrombin time, liver function tests (ALT, AST, ALP, GGT activities), total bilirubin, creatinine and minerals.

The adverse events (AE) were recorded as follows: any AE or serious adverse event (SAE), including any event requiring hospitalisation, life-threatening event, or death. The relation with the administered medication was also assessed. The haematological side effects (haemoglobin level $\leq 100 \mathrm{~g} / \mathrm{L}$, abnormal white blood cells $\leq 4,0 \times 10^{9} / \mathrm{L}$ or platelet count $\leq 70 \times 10^{9} / \mathrm{L}$ ), and liver toxicity (any abnormal ALT, AST, and bilirubin levels during treatment) were of special interest.

\section{Statistical analysis}

Data are presented as means, standard deviations, medians, and ranges, as appropriate. The changes in laboratory values at the particular therapy timepoints and during the follow-up were compared by the Kruskal-Wallis test. P value $<0.05$ was considered statistically significant throughout the study. Statistical analysis was performed using the R programming language v. 3.2.0 (www.r-project.org).

\section{Ethical standard}

This study was approved by the Ethics Committee of Thomayer's Hospital and the Institute for Clinical and Experimental Medicine, Prague, Czech Republic, and was carried out in compliance with the Helsinki Declaration.

The patients' informed consent was not required by local law because of the retrospective design of the study and the use of data from which the patients' identification information had been removed.

\section{Results}

\section{Treatment efficacy}

All 23 patients completed the planned 12-week course of treatment. All achieved negative viraemia on treatment and HCV RNA remained negative 12 weeks after the cessation of therapy (SVR 12 achievement). All 12 patients with elevated baseline ALT activity achieved ALT normalisation on PrOD treatment and remained within normal value ranges during the follow-up period.

Table 2. Adverse events overview. N., Number; AE, Adverse event; SAE, Serious adverse event. *no statistical difference between the groups in any parameter using Fischer's exact test

\begin{tabular}{lcc}
\hline & $\begin{array}{c}\text { Paritaprevir/Ritonavir/ } \\
\text { Ombitasvir/Dasabuvir } \\
\text { with Ribavirin (N=7) }\end{array}$ & $\begin{array}{c}\text { Paritaprevir/Ritonavir/ } \\
\text { Ombitasvir/Dasabuvir } \\
\text { without Ribavirin (N=16)* }\end{array}$ \\
\hline Any AE (N. of patients, \%) & $4(57.1 \%)$ & $8(50 \%)$ \\
Serious AE (N. of patients, \%) & $2(28.6 \%)$ & $2(12.5 \%)$ \\
Serious AE leading to medication discontinuation & $0(0 \%)$ & $0(0 \%)$ \\
AE & $1(14.3 \%)$ & $4(25 \%)$ \\
Nausea & $1(14.3 \%)$ & $2(12.5 \%)$ \\
Diarrhoea & $1(14.3 \%)$ & $1(6.25 \%)$ \\
Hyperkalemia & $1(14.3 \%)$ & $1(6.25 \%)$ \\
Hypotension & $1(14.3 \%)$ & $0(0 \%)$ \\
Respiratory infection & $0(0 \%)$ & $1(6.25 \%)$ \\
Urinary infection & & $1(6.25 \%)$ \\
SAE & $0(0 \%)$ & $1(6.25 \%)$ \\
Afunctional kidney graft rejection & $0(0 \%)$ & $0(0 \%)$ \\
Renal cyst infection & $1(14.3 \%)$ & $0(0 \%)$ \\
Early gastric cancer & $1(14.3 \%)$ & $0(0 \%)$ \\
Initiation of haemodialysis & $1(14.3 \%)$ & \\
Salmonellosis & & \\
\hline
\end{tabular}




\section{Kidney Blood Pressure Research}

Treatment tolerability

The treatment was generally well tolerated. Eleven patients (48\%) presented with at least one adverse event. The adverse events reported during treatment are listed in Table 2. The most frequent adverse events were nausea (5 patients), diarrhoea (3 patients), hypotension (2 patients), and hyperkalemia (2 CKD4 patients). These adverse events were mild and resolved without sequelae. Nausea and diarrhoea resolved spontaneously after the end of the treatment, hypotension resolved after adjustment of antihypertensive
Kidney Blood Press Res 2018;43:594-605

\begin{tabular}{l|l}
\hline DOI: $10.1159 / 000488965$ & (C) 2018 The Author(s). Published by S. Karger AG, Basel
\end{tabular}

Published onlıne: 17 April, $2018 \quad$ www.karger.com/kbr

Sperl et al.: Anti-HCV Therapy in Haemodialysed Patients

medication. Hyperkalemia in two CKD4 patients resolved after decrease or interruption of spironolactone.

Five adverse events in four patients during the treatment period were considered to be serious: the patients with SAE required hospital admission, but none of the events was considered to be related to antiviral treatment. One patient underwent gastrectomy on PrOD treatment. He presented with epigastric pain in the first week of treatment: gastric ulcer was found and an early-stage gastric cancer was diagnosed. The patient continued the PrOD treatment without interruption after gastrectomy (via nasojejunal feeding tube in the first week postoperatively) and achieved an SVR. The initiation of haemodialysis immediately after the operation in this patient was evaluated as a further SAE. The second patient presented with the retained kidney allograft rejection. He stopped immunosuppression shortly (only weeks) before PrOD treatment initiation. The patient underwent graftectomy on PrOD treatment and achieved an SVR as well. The third and fourth patient with SAE presented with severe bacterial infections (salmonellosis and renal cyst infection), both patients required intravenous antibiotic treatment with hospital admission.

The values of haemoglobin, leukocytes, and platelets during the treatment period and at week 12 after the end of therapy did not significantly differ from baseline values. There was no difference observed in haemoglobin values when comparing patients receiving RBV with the group without RBV (Fig. 1). None of the cirrhotic patients experienced decompensation during treatment and follow-up period. Consistently with the serum ALT activity normalisation, none of the patients presented with liver toxicity of PrOD regimen. None of the seven patients receiving ESA at baseline needed their dose escalation. In the patients without ESA baseline therapy, none had to initiate this therapy during the antiviral treatment course, independently of RBV administration.

One of the baseline CKD4 patients initiated maintenance haemodialysis subsequently to gastrectomy. The other three CKD4 patients had stable kidney function during the treatment period and the 12-week follow-up. Their GFR values were as follows: initially 26, 28 and 21 $\mathrm{ml} / \mathrm{min}$., at the end of therapy 35, 34, $18 \mathrm{ml} / \mathrm{min}$. and 34, 24 and $16 \mathrm{ml} / \mathrm{min}$. at week 12 after the end of therapy, respectively. 


\section{Kidney Blood Pressure Research}

Drug-drug interactions

The median number of concomitant drugs was 9 (range 5-18) in one patient. Concomitant medication had to be modified simultaneously with the treatment initiation in 10 out of 23 patients (43.5\%), two of whom required further adjustment of antihypertensive treatment during antiviral therapy and two other patients needed tacrolimus dose decrease on treatment. The most frequent drugs which had to be adjusted at the treatment initiation were: statins (3 patients), ACE inhibitors (6 patients), angiotensinII receptor inhibitors (2 patients), and diuretics (2 patients). The initial dose of tacrolimus had to be adjusted to 0.2 and $0.3 \mathrm{mg}$ weekly in two out of three patients, with one patient kept on the initial dose of 0.5 mg weekly. Subsequently, the tacrolimus level was in the therapeutic range and none of the patients experienced tacrolimus overdose or acute graft rejection owing to inadequate tacrolimus levels. After antiviral treatment cessation, all patients resumed their chronic concomitant medication during the first week posttreatment. The overview of concomitant medication adjustments is shown in Table 3.

\section{Discussion}

The PrOD regimen (with or without RBV) had an absolute efficacy in our group of CKD5 (haemodialysed) and CKD4 patients infected with HCV genotype 1, all of whom achieved SVR12. None of the patients discontinued treatment prematurely. The SVR rate in our group of patients is consistent with the results reported by other authors [13-16]. In the RUBY-I study, the achieved overall SVR rate was 90\% (intent-to-treat 95\%) in CKD4 and CKD5, genotype 1 infected patients. This study did not include patients with liver cirrhosis, more than half of whom were infected with HCV subtype 1a. The SVR rate in patients infected with HCV subtype $1 \mathrm{a}$ was lower than in patients infected with subtype $1 \mathrm{~b}$ as had been demonstrated in previous clinical trials dealing with patients with normal kidney function [10]. Contrarily, a universal SVR rate was achieved in the TURQUOISE-III study [11], which included sixty compensated cirrhotic patients infected with subtype $1 \mathrm{~b}$, even when the PrOD regimen was administered without RBV. Similar SVR rates (excellent or absolute) were described in two real-life cohorts of haemodialysed patients: the SVR rate in the study by Muñoz-Gómez et 


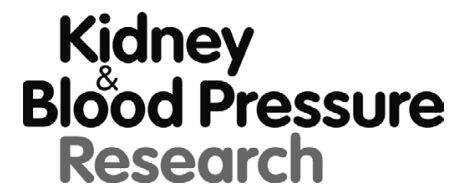

\begin{tabular}{l|l}
\hline Kidney Blood Press Res 2018;43:594-605 \\
\hline \begin{tabular}{l|l} 
DOI: 10.1159/000488965 & (c) 2018 The Author(s). Published by S. Karger AG, Basel \\
Published onlıne: 17 April, 2018 & ww.karger.com/kbr
\end{tabular} \\
\hline
\end{tabular}

Sperl et al.: Anti-HCV Therapy in Haemodialysed Patients

al. [15] was $95.7 \%$, where 2 out of 46 patients discontinued treatment for non-virological reasons, but the analysis evaluated patients infected with genotypes 1 and 4 together. Abad et al. [14] achieved an absolute SVR rate in a group of 35 haemodialysed patients infected with genotypes 1 and 4 . The explanation for the $100 \%$ SVR rate in our group of patients may be due to our patients being predominantly infected with HCV subtype $1 \mathrm{~b}$ (20 of $23,87 \%$ ).

Adding a reduced dose of RBV to PrOD did not have a negative impact on the achieved SVR rate. As the optimal RBV dose in haemodialysed patients has not been established so far, we compared the dose of RBV given to our patients ( $200 \mathrm{mg}$ twice a week) with the RBV dose used in RUBY-I study (200 mg once a day). Our decision to reduce the RBV dose was based on the high rate of RBV discontinuation in the RUBY-I study [13] and on the known RBV tolerability in our subgroup of treatment-experienced patients who had previously failed peginterferon- $\alpha$ and RBV treatment. Consistently with the current SPC of PrOD, RBV addition was needed only in subtype 1 a infected patients $[19,20]$. However, in the period during which we were starting treatment in most of the cirrhotic patients, RBV addition was recommended for subtype $1 \mathrm{~b}$ infected cirrhotics as well. Based on the result of TURQUOISE-III study [11], the recommendation was modified and the SPC was updated; PrOD combination without RBV was administered to the last cirrhotic subtype $1 \mathrm{~b}$ patient in our group.

Owing to the reduced dose of RBV, none of our patients needed ESA dose increase or blood transfusion and none of them developed anaemia. Anaemia was the most common AE in the RUBY-I study, and RBV was interrupted in 9 out of $13 \mathrm{HCV}$ subtype 1a patients to whom RBV was administered [13]. In the study by Muñoz-Gómez et al. [15], 16 out of 27 patients receiving ESA (10 of them treated with RBV), and in the study by Abad et al. [14], 15 out of 28 patients receiving ESA needed an increase of the ESA dose. We assume that the reduced RBV dose was the reason for different AEs profile in our cohort of patients. None of our patients complained of asthenia, while in the other three above-mentioned studies, asthenia was common. Asthenia represents a common symptom of anaemia and its absence in our group of patients is most likely associated with the absence of anaemia. The most common AE in our group was nausea; in general, it was mild and transient. Shortly after the ingestion of tablets, patients complained of nausea, which disappeared within hours.

We observed five SAEs in four patients. In our opinion, none of them was PrOD or RBV related. The patient who underwent gastrectomy for early gastric cancer on PrOD treatment presented with epigastric pain in the first week of the treatment. The cancer certainly developed before treatment initiation. The PrOD regimen has not an immunomodulatory effect. Neither acute rejection of the retained kidney graft nor the severe bacterial infections could be related to the PrOD treatment. The reason for the start of haemodialysis in the CKD4 patient with early gastric cancer was the major abdominal surgery, not the deterioration of the renal function owing to PrOD treatment. The remaining three CKD4 patients had stable renal function during treatment and follow-up period consistently with the reported absence of nephrotoxicity of PrOD regimen in registration trials. In accordance with the fact that PrOD regimen did not have a negative impact GFR in CKD4 patients, we evaluated the hyperkalemia in two patients as a consequence of potential drug-drug interaction between PrOD and spironolactone in severe kidney function impairment, which has not been described so far.

Based on our previous experience with peginterferon- $\alpha$-based regimens in haemodialysed patients who had a high rate of premature treatment termination [26], we consider the PrOD regimen as a regimen with excellent tolerability in this special group of patients.

As mentioned above, HCV infected patients on haemodialysis, who were referred to antiviral therapy shortly after the DAAs treatment regimens introduction, represent a group of patients with many comorbidities and with abundant concomitant medication. Those haemodialysed patients with HCV infection were waiting for an efficient treatment modality for several years [3]. The median number of concomitant drugs used by our patients was comparable with the number of drugs in the study by Muñoz-Gómez et al. [15]. The 


\section{Kidney Blood Pressure Research}

average age of patients in both groups is also comparable; 53.7 years in our patient group and 56.2 years in the above-mentioned study. Similarly to the published results, we had to adjust concomitant medication in $43.5 \%$ of the patients before antiviral treatment. The most frequent drugs which had to be adjusted included statins, ACE inhibitors, angiotensinII receptor inhibitors, and diuretics. In contrast, we had to make further medication adjustments after starting antiviral treatment (in 4 patients, 16.7\%) because of hypotension and hyperkalemia or tacrolimus dosage adjustment. This fact underlines the need for careful monitoring of blood pressure and laboratory parameters after starting the treatment. The adjustment of tacrolimus dose is of high importance in patients with another organ graft. Regular tacrolimus blood level monitoring is the only way to avoid tacrolimus levels fluctuation, which can lead to the risk of acute graft rejection or tacrolimus toxicity. The weekly tacrolimus dose of $0.2-0.5 \mathrm{mg}$ turned out to be an optimal approach. In contrast to the sofosbuvir-based treatment regimens [27], in PrOD regimen, patients may continue omeprazole administration without treatment efficacy alterations. This is important especially in haemodialysed patients, who have a higher risk of gastrointestinal bleeding in comparison with general population [28, 29]. They often use low-dose aspirin or other antiplatelet agents to prevent the arteriovenous fistula occlusion, and they are regularly given anticoagulants during haemodialysis sessions.

Finally, the use of amiodarone may lead to a perilous drug-drug interaction with PrOD regimen (risk of severe bradycardia or cardiac arrest in elevated plasma amiodarone levels) [30]. There is no safe antiviral treatment alternative; amiodarone is incompatible with sofosbuvir-based regimens [31], and grazoprevir and elbasvir regimen administration with amiodarone has not been studied yet [32]. The only option for allowing antiviral treatment in patients on amiodarone is stopping its administration and replacing it by another antiarrhythmic. We were not able to start the PrOD treatment in two patients on amiodarone referred to the antiviral treatment in the same period, but both were ready to start treatment shortly. We successfully substituted propafenone for amiodarone in one of the patients. In the second patient, amiodarone treatment was stopped after mitral valve replacement, and the patient remained stable on betablocker therapy. In both patients, the weaning period of three months had to follow after amiodarone cessation.

The retrospective studies are generally considered to be inappropriate for the evaluation of adverse events and drug-drug interactions. On the other hand, haemodialysed patients represent a group of patients with the most accurate medical records. Haemodialysed patients in our study had three visits a week and the CKD4 patients were followed up on a monthly or bimonthly basis. Using the same structured recording system in all haemodialysis units in the Czech Republic allowed a precise retrospective analysis of concomitant medication and adverse events despite the patients being treated in different haemodialysis units.

\section{Conclusion}

We conclude that despite numerous drug-drug interactions of PrOD regimen, it may be administered to almost all CKD4 and haemodialysed patients after a careful initial adjustment of concomitant medication and with cautious monitoring, especially in the initial phase of the treatment.

\section{Acknowledgements}

The authors thank referring nephrologists for providing patients' laboratory data and concomitant medication reports: Pavel Konopasek, Katerina Kotherova, Vratislava Kovarova, Jan Kubat, Miroslav Merta, Eva Rozmankova, Lukas Svoboda, Petr Taborsky, Monika Tothova, Katerina Veselovska, Jiri Vlasak. 


\section{Kidney Blood Pressure Research}

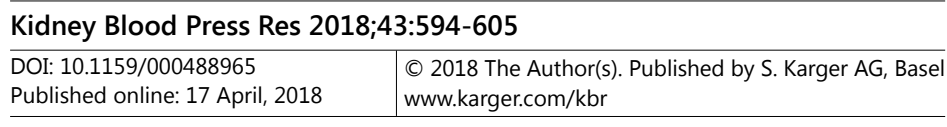

Sperl et al.: Anti-HCV Therapy in Haemodialysed Patients

\section{Disclosure Statement}

Dr. Sperl reports grants and personal fees from Abbvie, Merck, Gilead, BMS and Herbacos Recordati, outside the submitted work. Dr. Frankova reports personal fees from BMS, MSD, Abbvie, Gilead and Novartis, outside the submitted work. Dr. Merta, Dr. Chmelova, Dr. Senkerikova and Dr. Kreidlova have nothing to disclose. We report financial support by MH CZ - DRO („Institute for Clinical and Experimental Medicine - IKEM, IN 00023001“).

\section{References}

1 Mathurin P, Mouquet C, Poynard T, Sylla C, Benalia H, Fretz C, Thibault V, Cadranel JF, Bernard B, Opolon P, Coriat P, Bitker MO: Impact of hepatitis B and C virus on kidney transplantation outcome. Hepatology 1999;29:257-263.

2 Okino K, Okushi Y, Mukai K, Matsui Y, Hayashi N, Fujimoto K, Adachi H, Yamaya H, Yokoyama H: The longterm outcomes of hepatitis $\mathrm{C}$ virus core antigen-positive Japanese renal allograft recipients. Clin Exp Nephrol 2017;21:1113-1123.

- Goodkin DA, Bieber B, Gillespie B, Robinson BM, Jadoul M: Hepatitis C infection is very rarely treated among hemodialysis patients. Am J Nephrol 2013;38:405-412.

4 Peck-Radosavljevic M, Boletis J, Besisik F, Ferraz ML, Alric L, Samuel D, Messinger D, Tietz A, Cheinquer $\mathrm{H}$ : Low-dose peginterferon alfa-2a is safe and produces a sustained virologic response in patients with chronic hepatitis C and end-stage renal disease. Clin Gastroenterol Hepatol 2011;9:242-248.

5 European Association for the Study of the Liver: EASL Recommendations on Treatment of Hepatitis C 2016. J Hepatol 2017;66:153-194.

6 Kwo PY, Mantry PS, Coakley E, Te HS, Vargas HE, Brown R Jr, Gordon F, Levitsky J, Terrault NA, Burton JR Jr, Xie W, Setze C, Badri P, Pilot-Matias T, Vilchez RA, Forns X: An interferon-free antiviral regimen for HCV after liver transplantation. N Engl J Med 2014;371:2375-2382.

7 Feld JJ, Kowdley KV, Coakley E, Sigal S, Nelson DR, Crawford D, Weiland O, Aguilar H, Xiong J, Pilot-Matias T, DaSilva-Tillmann B, Larsen L, Podsadecki T, Bernstein B: Treatment of HCV with ABT-450/r-ombitasvir and dasabuvir with ribavirin. N Engl J Med 2014;370:1594-1603.

-8 Zeuzem S, Jacobson IM, Baykal T, Marinho RT, Poordad F, Bourlière M, Sulkowski MS, Wedemeyer H, Tam E, Desmond P, Jensen DM, Di Bisceglie AM, Varunok P, Hassanein T, Xiong J, Pilot-Matias T, DaSilva-Tillmann B, Larsen L, Podsadecki T, Bernstein B: Retreatment of HCV with ABT-450/r-ombitasvir and dasabuvir with ribavirin. N Engl J Med 2014;370:1604-1614.

-9 Ferenci P, Bernstein D, Lalezari J, Cohen D, Luo Y, Cooper C, Tam E, Marinho RT, Tsai N, Nyberg A, Box TD, Younes Z, Enayati P, Green S, Baruch Y, Bhandari BR, Caruntu FA, Sepe T, Chulanov V, Janczewska E, et al.: ABT-450/r-ombitasvir and dasabuvir with or without ribavirin for HCV. N Engl J Med 2014;370:19831992.

10 Poordad F, Hezode C, Trinh R, Kowdley KV, Zeuzem S, Agarwal K, Shiffman ML, Wedemeyer H, Berg T, Yoshida EM, Forns X, Lovell SS, Da Silva-Tillmann B, Collins CA, Campbell AL, Podsadecki T, Bernstein B: ABT-450/r-ombitasvir and dasabuvir with ribavirin for hepatitis C with cirrhosis. N Engl J Med 2014;370:1973-1982.

11 Feld JJ, Moreno C, Trinh R, Tam E, Bourgeois S, Horsmans Y, Elkhashab M, Bernstein DE, Younes Z, Reindollar RW, Larsen L, Fu B, Howieson K, Polepally AR, Pangerl A, Shulman NS, Poordad F: Sustained virologic response of $100 \%$ in HCV genotype $1 \mathrm{~b}$ patients with cirrhosis receiving ombitasvir/ paritaprevir/r and dasabuvir for 12weeks. J Hepatol 2016;64:301-307.

12 Krishnan P, Tripathi R, Schnell G, Reisch T, Beyer J, Irvin M, Xie W, Larsen L, Cohen D, Podsadecki T, PilotMatias T, Collins C: Resistance analysis of baseline and treatment-emergent variants in hepatitis $\mathrm{C}$ virus genotype 1 in the AVIATOR study with paritaprevir-ritonavir, ombitasvir, and dasabuvir. Antimicrob Agents Chemother 2015;59:5445-5454. 


\section{Kidney \\ Blood Pressure Research}

\begin{tabular}{l|l}
\hline Kidney Blood Press Res 2018;43:594-605 \\
\hline $\begin{array}{ll}\text { DOI: 10.1159/000488965 } & \text { (c) } 2018 \text { The Author(s). Published by S. Karger AG, Basel } \\
\text { wublished online: 17 April, } 2018 & \text { www.karger.com/kbr }\end{array}$ \\
\hline
\end{tabular}

Sperl et al.: Anti-HCV Therapy in Haemodialysed Patients

13 Pockros PJ, Reddy KR, Mantry PS, Cohen E, Bennett M, Sulkowski MS, Bernstein DE, Cohen DE, Shulman NS, Wang D, Khatri A, Abunimeh M, Podsadecki T, Lawitz E: Efficacy of Direct-Acting Antiviral Combination for Patients With Hepatitis C Virus Genotype 1 Infection and Severe Renal Impairment or End-Stage Renal Disease. Gastroenterology 2016;150:1590-1598.

-14 Abad S, Vega A, Hernandez E, Mérida E, de Sequera P, Albalate M, Macías N, Milla M, López-Gómez JM: Universal Sustained Viral Response to the Combination of Ombitasvir/Paritaprevir/Ritonavir and Dasabuvir with/without Ribavirin in Patients on Hemodialysis Infected with Hepatitis C Virus Genotypes 1 and 4. Am J Nephrol 2017;45:267-272.

-15 Munoz-Gomez R, Rincon D, Ahumada A, Hernández E, Devesa MJ, Izquierdo S, Ortiz M, Hernández-Albujar A, Fernández-Rodríguez C, Calvo M, González R, Lozano M, Castellano G, Fernández-Vázquez I: Therapy with ombitasvir/paritaprevir/ritonavir plus dasabuvir is effective and safe for the treatment of genotypes 1 and 4 hepatitis $\mathrm{C}$ virus (HCV) infection in patients with severe renal impairment: A multicentre experience. J Viral Hepat 2017;24:464-471.

-16 Ponziani FR, Siciliano M, Lionetti R, Pasquazzi C, Gianserra L, D’Offizi G, Gasbarrini A, Pompili M: Effectiveness of Paritaprevir/Ritonavir/Ombitasvir/Dasabuvir in Hemodialysis Patients With Hepatitis C Virus Infection and Advanced Liver Fibrosis: Case Reports. Am J Kidney Dis 2017;70:297-300.

-17 Sato K, Hosonuma K, Yamazaki Y, Kobayashi T, Takakusagi S, Horiguchi N, Kakizaki S, Kusano M, Ohnishi H, Okamoto H, Yamada M: Combination Therapy with Ombitasvir/Paritaprevir/Ritonavir for Dialysis Patients Infected with Hepatitis C Virus: A Prospective Multi-Institutional Study. Tohoku J Exp Med 2017;241:45-53.

-18 Smith MA, Lim A: Profile of paritaprevir/ritonavir/ombitasvir plus dasabuvir in the treatment of chronic hepatitis C virus genotype 1 infection. Drug Des Devel Ther 2015;9:6083-6094.

19 SPC Viekirax: http://www.ema.europa.eu/docs/cs_CZ/document_library/EPAR_-_Product_Information/ human/003839/WC500183997.pdf.

20 SPC Exviera: http://www.ema.europa.eu/docs/cs_CZ/document_library/EPAR_-_Product_Information/ human/003837/WC500182233.pdf.

21 Lassalle M, Ayav C, Frimat L, Jacquelinet C, Couchoud C: The essential of 2012 results from the French Renal Epidemiology and Information Network (REIN) ESRD registry. Nephrol Ther 2015;11:78-87.

22 Shafi T, Sozio SM, Luly J, Bandeen-Roche KJ, St Peter WL, Ephraim PL, McDermott A, Herzog CA, Crews DC, Scialla JJ, Tangri N, Miskulin DC, Michels WM, Jaar BG, Zager PG, Meyer KB, Wu AW, Boulware LE: Antihypertensive medications and risk of death and hospitalizations in US hemodialysis patients: Evidence from a cohort study to inform hypertension treatment practices. Medicine (Baltimore) 2017;96:e5924.

-23 Levey AS, de Jong PE, Coresh J, El Nahas M, Astor BC, Matsushita K, Gansevoort RT, Kasiske BL, Eckardt KU: The definition, classification, and prognosis of chronic kidney disease: a KDIGO Controversies Conference report. Kidney Int 2011;80:17-28.

24 Gerber L, Kasper D, Fitting D, Knop V, Vermehren A, Sprinzl K, Hansmann ML, Herrmann E, Bojunga J, Albert J, Sarrazin C, Zeuzem S, Friedrich-Rust M: Assessment of liver fibrosis with 2-D shear wave elastography in comparison to transient elastography and acoustic radiation force impulse imaging in patients with chronic liver disease. Ultrasound Med Biol 2015;41:2350-2359.

-25 European Association for Study of Liver: EASL Clinical Practice Guidelines: management of hepatitis C virus infection. J Hepatol 2014;60:392-420.

-26 Sperl J, Frankova S, Senkerikova R, Neroldova M, Hejda V, Volfova M, Merta D, Viklicky O, Spicak J, Jirsa M: Relevance of low viral load in haemodialysed patients with chronic hepatitis C virus infection. World J Gastroenterol 2015;21:5496-5504.

-27 Tapper EB, Bacon BR, Curry MP, Dieterich DT, Flamm SL, Guest LE, Kowdley KV, Lee Y, Tsai NC, Younossi ZM, Afdhal NH: Evaluation of proton pump inhibitor use on treatment outcomes with ledipasvir and sofosbuvir in a real-world cohort study. Hepatology 2016;64:1893-1899.

-28 Ishigami J, Grams ME, Naik RP, Coresh J, Matsushita K: Chronic Kidney Disease and Risk for Gastrointestinal Bleeding in the Community: The Atherosclerosis Risk in Communities (ARIC) Study. Clin J Am Nephrol 2016;11:1735-1743.

29 Lee YC, Hung SY, Wang HH, Wang HK, Lin CW, Chang MY, Ho LC, Chen YT, Wu CF, Chen HC, Wang WM, Sung JM, Chiou YY, Lin SH: Different Risk of Common Gastrointestinal Disease Between Groups Undergoing Hemodialysis or Peritoneal Dialysis or With Non-End Stage Renal Disease: A Nationwide Population-Based Cohort Study. Medicine 2015;94:e1482. 


\section{Kidney

-30 Renet S, Chaumais MC, Antonini T, Zhao A, Thomas L, Savoure A, Samuel D, Duclos-Vallée JC, Algalarrondo V: Extreme bradycardia after first doses of sofosbuvir and daclatasvir in patients receiving amiodarone: 2 cases including a rechallenge. Gastroenterology 2015;149:1378-1380.e1.

-31 Desnoyer A, Pospai D, Le MP, Gervais A, Heurgué-Berlot A, Laradi A, Harent S, Pinto A, Salmon D, Hillaire S, Fontaine H, Zucman D, Simonpoli AM, Muret P, Larrouy L, Bernard Chabert B, Descamps D, Yazdanpanah Y, Peytavin G: Pharmacokinetics, safety and efficacy of a full dose sofosbuvir-based regimen given daily in hemodialysis patients with chronic hepatitis C. J Hepatol 2016;65:40-47.

-32 Roth D, Nelson DR, Bruchfeld A, Liapakis A, Silva M, Monsour H Jr, Martin P, Pol S, Londoño MC, Hassanein T, Zamor PJ, Zuckerman E, Wan S, Jackson B, Nguyen BY, Robertson M, Barr E, Wahl J, Greaves W: Grazoprevir plus elbasvir in treatment-naive and treatment-experienced patients with hepatitis $C$ virus genotype 1 infection and stage 4-5 chronic kidney disease (the C-SURFER study): a combination phase 3 study. Lancet 2015;386:1537-1545. 